九州大学学術情報リポジトリ

Kyushu University Institutional Repository

\title{
Taxonomic Position of Chionaspis miyakoensis (Homoptera: Coccoidea: Diaspididae)
}

Shoubu, Megumi

Entomological Laboratory, Graduate School of Bioresource and Bioenvironmental Science, Kyushu University

Kawai, Shozo

Laboratory of Tropical Plant Protection, Tokyo University of Agriculture

https://doi.org/10.5109/2665

出版情報: ESAKIA. 42, pp.151-160，2002-03-31. Entomological Laboratory，Faculty of Agriculture, Kyushu University

バージョン：

権利関係 : 


\title{
Taxomomic Position of Chionaspis miyakoensis (Homoptera: Coccoidea: Diaspididae)*
}

\author{
Megumi SHOUBU \\ Entomological Laboratory, Graduated School of Bioresource and Bioenvironmental Science, \\ Kyushu University, Fukuoka, 812-8581 Japan \\ and \\ Shôzo KAWAI \\ Laboratory of Tropical Plant Protection, Tokyo University of Agriculture, \\ Tokyo, 156-8502 Japan
}

\begin{abstract}
Chionaspis miyakoensis Kuwana 1931 was synonymized with Pseudaulacaspis cockerelli (Cooley, 1897) in Takagi (1970). However, our morphological study of their second instar males revealed that they are clearly distinguishable from each other in the males, in spite of their resemblance in the adult females. We redescribe the adult female and, for the first time, the second instar male of $C$. miyakoensis, and raise it to the species level again as Pseudaulacaspis miyakoensis.
\end{abstract}

Key words: taxonomy, Homoptera, Coccoidea, Diaspididae, Pseudaulacaspis, second instar male

\section{Introduction}

The genus Pseudaulacaspis consists of at least 70 nominal species in the world (e.g. Borchsenius, 1966; Takagi, 1985). Some of them were synonymized with Pseudaulacaspis cockerelli (Cooley, 1897) (e.g. Ferris, 1956; Takagi, 1961; Takagi, 1970), which is a widespread and polyphagous species infesting a large number of woody plants (Borchsenius, 1966). Pseudaulacaspis cockerelli is variable in the body shape, the number and

\footnotetext{
* Contribution from the Entomological Laboratory, Faculty of Agriculture, Kyushu University,
} Fukuoka (Ser. 5, No. 82). 
arrangement of the dorsal macroducts, the number of the disc pores and gland spines and other characters (Takagi, 1970). Therefore Kawai (1980) temporarily divided it into 4 forms ("biformis form", "cockerelli form", "miyakoensis form", and "sandwicensis form"), which had been originally described as independent species.

Among these forms, miyakoensis that is treated in this paper was first described as a species of the genus Chionaspis by Kuwana (1931) and then combined with $P$. cockerelli by Takagi (1970). However, our recent study of the second instar males revealed that miyakoensis could be distinguished from $P$. cockerelli and raised again to the species level as Pseudaulacaspis miyakoensis. In this paper we refer to some adult female features that were not or fully described in the original description of $P$. miyakoensis. In addition, we newly describe the second instar male by paying special attention to the status of modified ducts.

Before going further, we wish to express our sincere gratitude to Prof. Junichi Yukawa of the Entomological Laboratory, Kyushu University for his critical review of the manuscript and helpful comments for the present study.

\section{Materials and Methods}

This study is based on the specimens collected by us from 1965 to 2001 . Collection data of the specimens are shown in Table 1.

All examined specimens that were collected by Kawai are deposited in the Kawai's collection, Laboratory of Tropical Plant Protection, Tokyo University of Agriculture, Tokyo, Japan. Other specimens are deposited in the Entomological Laboratory, Kyushu University, Fukuoka Pref., Japan. We adopted the method presented by Kawai (1980) for the preparation of slide-mounted specimens. In the description of species, the first to eighth abdominal segments were abbreviated as "Abd.I, Abd.II, ..., and Abd.VIII". The terms "bark-form" and "leaf-form" have usually been used by previous authors, but in this paper, we adopt the terms "bark-type" and "leaf-type" in place of them, in order to avoid confusing "barkform" and "leaf-form" with the three forms of $P$. cockerelli.

\section{Description}

Pseudaulacaspis miyakoensis (Kuwana, 1931) stat. rev.

Chionaspis miyakoensis Kuwana, 1931: 647, 649; Takahashi, 1953: 54, 56.

Phenacaspis miyakoensis: Ferris, 1955: 51. 


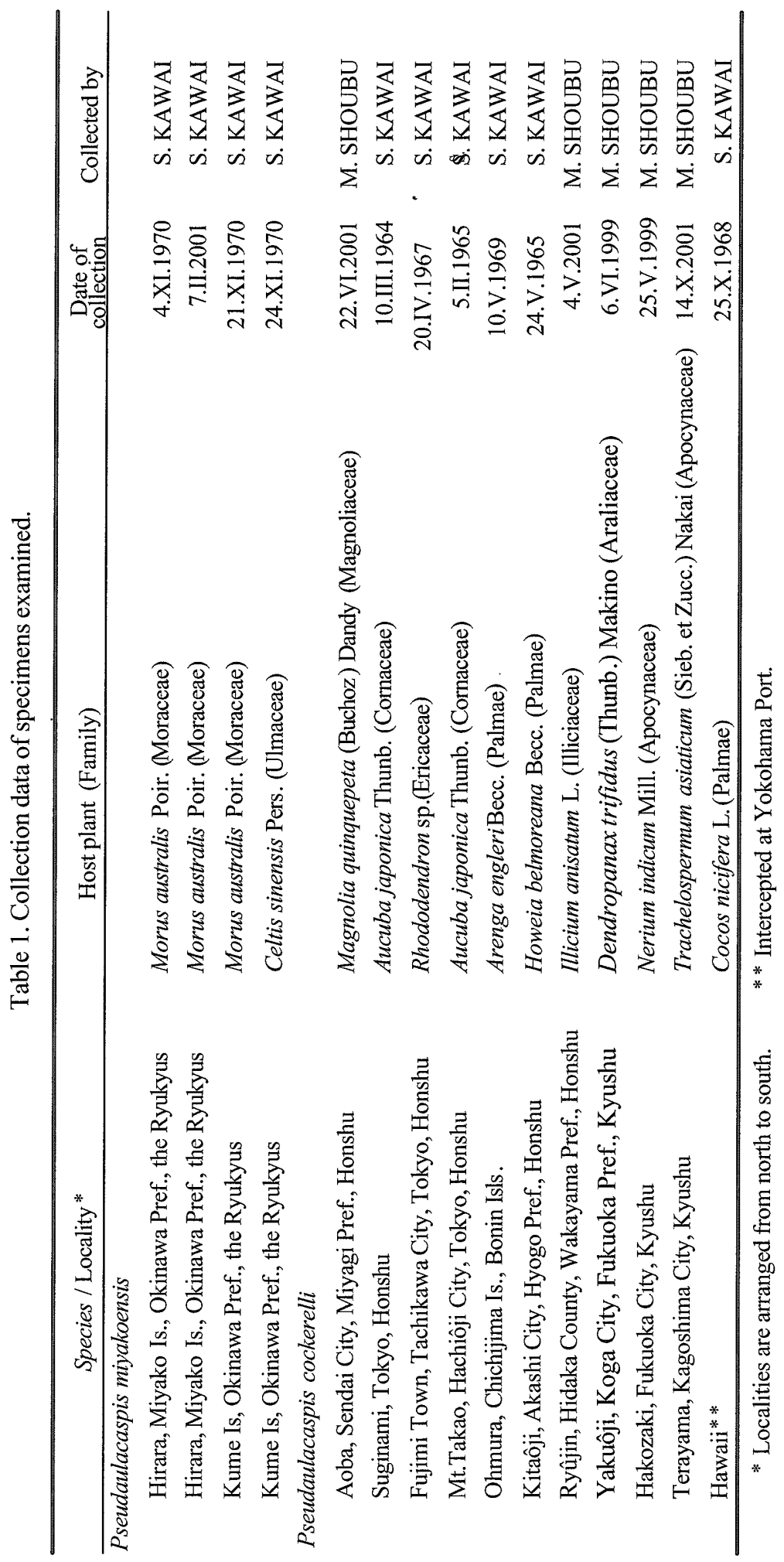




\section{Redescription of Adult Female (Fig.1)}

Body robust and fusiform, broadest at abdominal base (Fig.1A); body $0.7-0.9 \mathrm{~mm}$ long and $0.4-0.5 \mathrm{~mm}$ wide at Abd.I slide-mounted specimens; meso- and metathorax and basal three abdominal segments moderately lobed laterally. Antennae located a little posteriorly to frontal margin, adjacent each other, each with a seta. Anterior spiracles each with 6 - 12 clustered accompanying disc pores, posterior spiracles without disc pores. One or two tiny gland tubercles always occurring on mesothorax on ventrum. Dorsal macroducts arranged in caudal rows along margins of Abd.II to $\mathrm{V}$, and each row divided into submedian and submarginal series. Pygidium rounded or somewhat triangular. A pair of median lobes and a pair of second lobes present (Fig.1B); median lobes in the bark-type robust, entirely prominent, zygotic basally, apical margin serrate; median lobes in the leaf-type sunken into pygidium, and not robust. Second lobes bilobulate; inner lobule entirely chitinized, with 2 well developed club-shaped paraphyses at base; outer lobule reduced into a triangular and pointed process; in the leaf-type, outer lobule sometimes well developed. Pygidial marginal macroducts arranged as usual in Pseudaulacaspis, one on Abd.VII, 2 on Abd.VI and V. Perivulvar disc pores arranged in 5 groups, 4-8 pores in the median group, 12-23 on each anterolateral group and 11-22 on each posterolateral group. Preanal scars quite distinct. See Table 2 for the number of gland spines and dorsal macroducts.

Table 2. Number of dorsal macroducts and gland spines in the adult female of Pseudaulacaspis miyakoensis.

\begin{tabular}{rccc}
\hline & $\begin{array}{c}\text { Submedian } \\
\text { DM }\end{array}$ & $\begin{array}{c}\text { Submarginal } \\
\text { DM }\end{array}$ & Gland spines \\
\hline Mesothorax & -- & -- & $1-3$ \\
Metathorax & -- & -- & $2-7$ \\
Abd. I & -- & - & $2-5$ \\
Abd. II & $2-8$ & $6-10$ & $2-6$ \\
Abd. III & $3-9$ & $4-10$ & $2-6$ \\
Abd. IV & $3-5$ & $4-7$ & $1-3$ \\
Abd. V & $2-4$ & $2-6$ & 1 \\
Abd. VI & $0-2$ & -- & 1 \\
Abd. VII & -- & -- & 1 \\
Abd. VIII & -- & - & 1 \\
\hline *Dorsal macroducts & &
\end{tabular}

*Dorsal macroducts. 


\section{Description of Second Instar Male (Fig.2)}

Body oval, membraneous. Antenna each with a seta. Anterior spiracles usually each with 2 disc pores; posterior spiracle without disc pores. Margin of Abd.VI and VII rugged with sclerotized dantations. A pair of serrate, sclerotized lobes present on the posterior margin of pygidium (Abd.VIII), widely separated from each other. "Communal ducts" (Tippins 1970, known as "glanduliferous crater" in Takagi 1999) absent. "Cluster ducts" (Tippins, 1970) consisting of 5-11 short ducts each with relatively large orifices, present marginally from Abd.VI to VII. Marginal duct similar in shape to a component of cluster ducts, 1 present on each side of Abd.II, 1-3 on Abd.III, and 2-4 on Abd.IV. Marginal setae on Abd.IV-VII elongate. Dorsal macroducts scattered broadly in marginal and submarginal regions of thorax and in anterior abdominal segments; dorsal macroducts on submarginal region of abdomen arranged in longitudinal bands. Ventral microducts scattered submarginally on cephalothorax, and arranged in 3 longitudinal rows on abdomen. Gland spines well-developed, of which 1-3 (usually 2) present posterolaterally to anterior spiracle, 1 laterally to posterior spiracle, 2-3 submarginally on Abd.I. A small, rather vestigial gland spine occurring marginally on each of Abd.II-V.

\section{Discussion}

The genus Pseudaulacaspis is known to exhibit site-caused polymorphism; in general, individuals occur on bark have robust and prominent median lobes (bark-type); while those on leaves have median lobes that are not robust and sunken into the pygidium (leaftype) (Takagi, 1990).

The "cockerelli form" of $P$. cockerelli has both bark- and leaf-type, the "biformis form" is represented by the bark-type alone, and the "sandwicensis form" consists of the leaf-type alone (Kawai, 1980). Pseudaulacaspis miyakoensis was originally described for the bark-type (Kuwana, 1931) and thereafter Takahashi (1953) briefly reported the leaftype of this species.

Pseudaulacaspis miyakoensis was treated as the bark-type of $P$. cockerelli ("cockerelli form") in Takagi (1961) based on the following characters of the pygidium: median lobes prominent; inner lobule of second lobes sclerotized strongly with club-shaped paraphyses at their base; outer lobule reduced into a small apically pointed process. These characters are common in some individuals of the two species and cannot be used to discriminate from each other. The present study revealed that $P$. miyakoensis can be distinguished from the "cockerelli form" by having each of the fifth to eighth abdominal segments with only one marginal gland spine.

Takagi (1961) did not refer to the leaf-type of P. miyakoensis. In this study, we had difficulties in distinguishing the leaf-type of $P$. miyakoensis from the "sandwicensis form" 
of $P$. cockerelli, because they are very similar to each other in the shape of median lobes and the number of marginal gland spines on the pygidium. However we found differences between the leaf-type of $P$. miyakoensis and the "sandwicensis form" as follows: the former has club-shaped paraphyses of inner lobule of second lobes and distinct preanal scars and frequently lacks submedian dorsal macroducts on the sixth abdominal segment.

Contrary to the morphological variations in adult females, the second instar males of $P$. cockerelli are considered to be uniform, since the sixth abdominal communal ducts and the sixth-seventh abdominal cluster ducts, which are outstanding characters of the second instar males, were common in all individuals examined (Fig. 3). The second instar males of $P$. miyakoensis are also uniform.

Although the differences in adult females seem to be trifling and insignificant for separating the two species, the second instar males are remarkably different between them (compare Figs. 2 and 3). Pseudaulacaspis miyakoensis differs from $P$. cockerelli in the lack of communal ducts and in the possession of cluster ducts alone on the sixth-seventh abdominal segments. Similar examples have been known for the genera Fiorinia (Tippins, 1970) and Aulacaspis (Takagi, 1998), in which species were clearly distinguished by the second instar males rather than by adult females.

Chionaspis akebiae Takahashi was treated as a synonym of miyakoensis in Ferris (1956). However the drawing of the type specimen of C. akebiae (Takagi, 1961) indicates that it differs from $P$. miyakoensis and should be synonymyzed with $P$. cockerelli by the presence of plural marginal gland spines on the fifth abdominal segment.

\section{References}

Borchsenius, N. S., 1966. A Catalog of the Armoured Scale Insects (Diaspidoidea) of the World. Akademia Nauk SSSR Zoologicheskii Institut, Moscow and Leningrad, 449 pp. (In Russian.)

Ferris, G. F., 1955. The genus Phenacaspis Cooley and Cockerell. Part I (Insecta: Homoptera: Coccoidea). Microentomology, 20 (3): 41-54.

Ferris , G. F., 1956. The genus Phenacaspis Cooley and Cockerell. Part II (Insecta: Homoptera: Coccoidea). Microentomology, 21 (2): 67-74.

Kawai, S., 1980. Scale Insects of Japan in Colors. Noson Kyoiku-Kyokai, Tokyo, 455 pp. (In Japanese.)

Kuwana, I., 1931. New scale insects and white fly found upon plants entering Japanese ports. Dobutsugaku-Zasshi, 43 (517): 647-660. (In Japanese with English summary.)

Takagi, S., 1961. A contribution to the knowledge of the Diaspidini of Japan (Homoptera: Coccoidea). Part II. Ins. Mats., 24 (1): 4-103.

Takagi, S., 1970. Diaspididae of Taiwan based on material collected in connection with 
the Japan-U. S. Co-operative Science Programme, 1965 (Homoptera: Coccoidea). Part II. Ins. Mats., 33 (1): 1-146.

Takagi, S., 1990. 1.1.2.6. Polymorphism. In Rosen, D. (ed.): Armored Scale Insects, Their Biology, Natural Enemies and Control. World Crop Pests 4A. Elsevier, 384 pp.

Takagi, S., 1998. A new mangrove-infesting species of Aulacaspis occurring in Southeast Asia, with a revision of $A$. vitis (Homoptera: Coccoidea: Diaspididae). Ins. Mats. N. S., 54: 51-76.

Takagi, S., 1999. Notes on the scale insect subtribe Kuwanaspidina (Homoptera: Coccoidea: Diaspididae). Ins. Mats. N. S., 56: 95-150.

Takahashi, R., 1953. Dimorphism in some species of Chionaspis or Phenacaspis (Diaspididae, Coccoidea, Homoptera). Boll. Lab. Zool. Gener. Agr. (Filippo Silvestri), Portici, 33: 48-56.

Tippins, H. H., 1970. The second instar males of three species of Fiorinia (Homoptera: Diaspididae). J. Georgia Ent. Soc., 5: 94-99. 


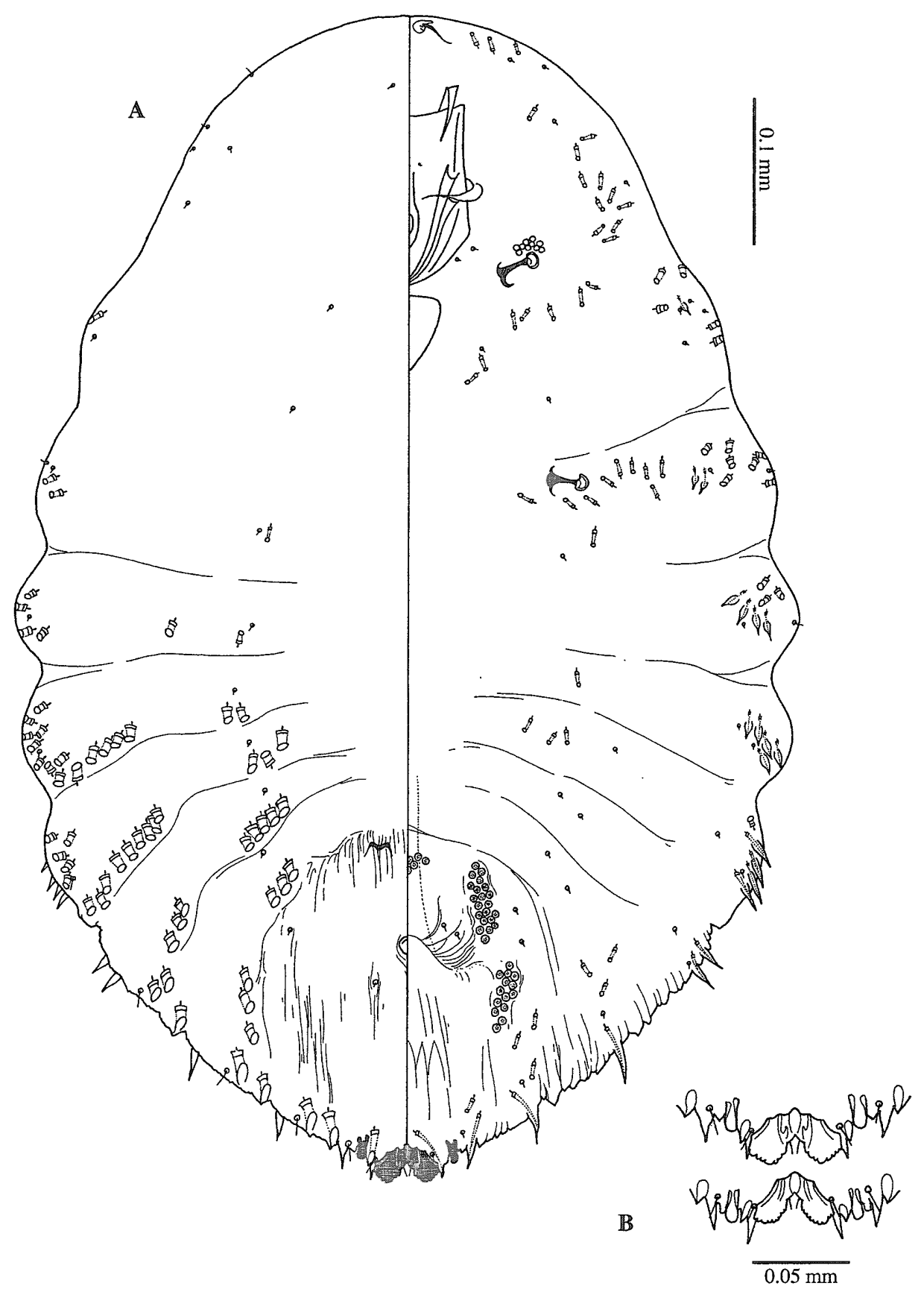

Fig. 1. Pseudaulacaspis miyakoensis (Kuwana), adult female; A, body; B, median and second lobes, above bark-type, below leaf-type. 


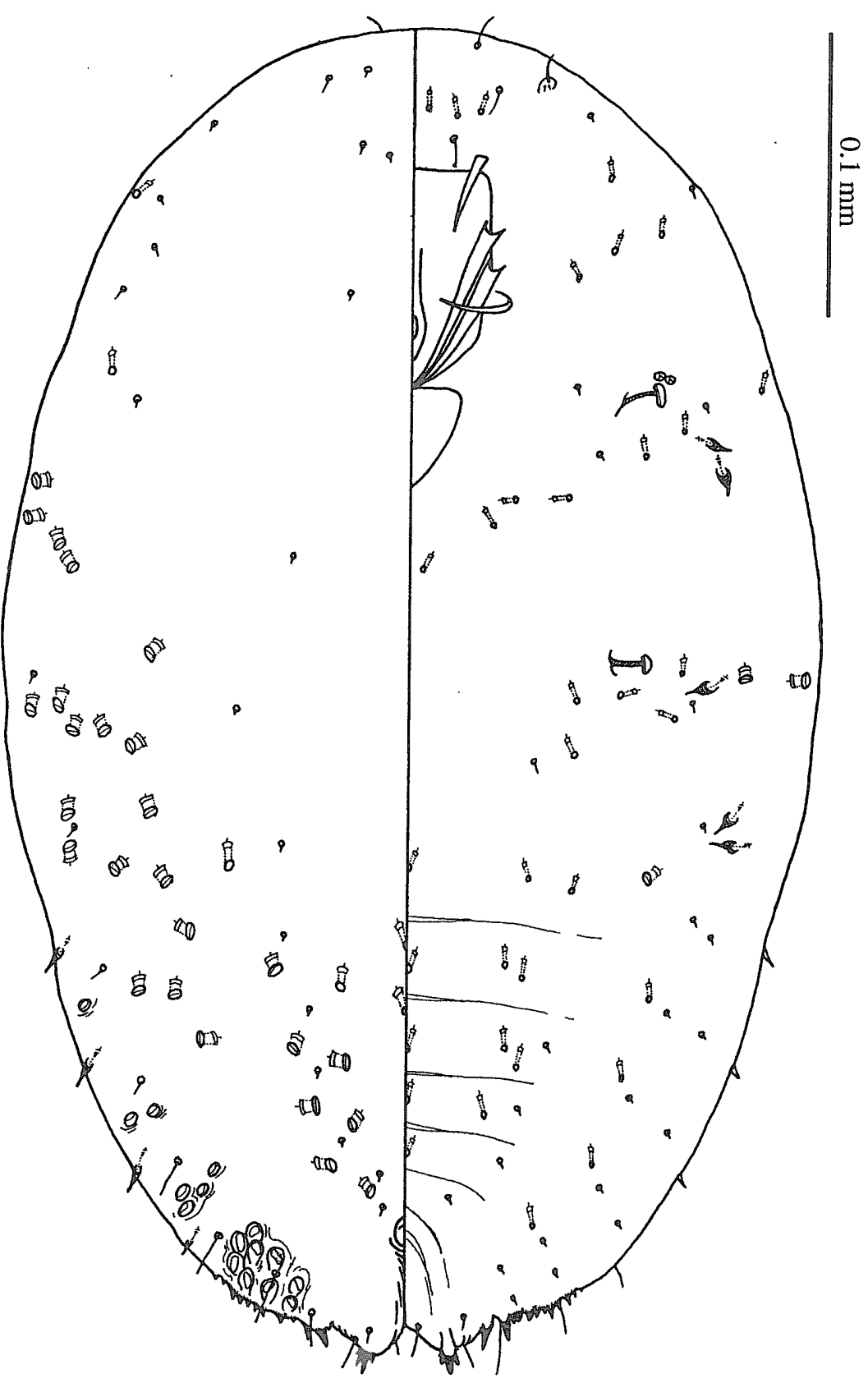

Fig. 2. Pseudaulacaspis miyakoensis (Kuwana), second instar male. 


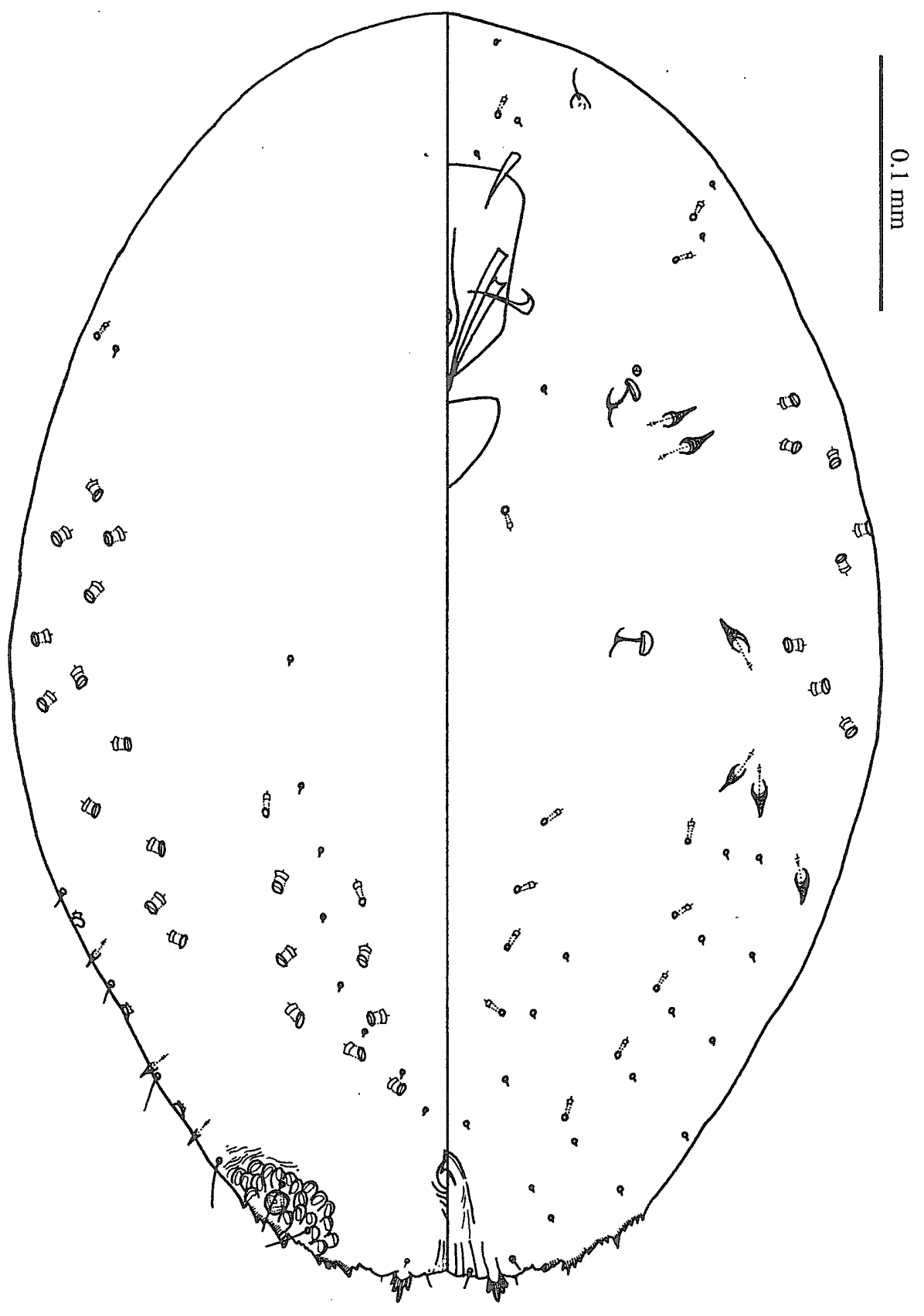

Fig. 3. Pseudaulacaspis cockerelli (Cooley), second instar male. 